\title{
Absence of Rybp Compromises Neural Differentiation of Embryonic Stem Cells
}

\author{
Gergo Kovacs, Viktoria Szabo, and Melinda K. Pirity \\ Institute of Genetics, Laboratory of Embryonic and Induced Pluripotent Stem Cells, Biological Research Centre, \\ Hungarian Academy of Sciences, Temesvári krt. 62, Szeged 6726, Hungary
}

Correspondence should be addressed to Melinda K. Pirity; pirity.melinda@brc.mta.hu

Received 30 June 2015; Revised 11 August 2015; Accepted 16 August 2015

Academic Editor: Su-Chun Zhang

Copyright (c) 2016 Gergo Kovacs et al. This is an open access article distributed under the Creative Commons Attribution License, which permits unrestricted use, distribution, and reproduction in any medium, provided the original work is properly cited.

Rybp (Ringl and Yyl Binding Protein) is a transcriptional regulator and member of the noncanonical polycomb repressive complex 1 with essential role in early embryonic development. We have previously described that alteration of Rybp dosage in mouse models induced striking neural tube defects (NTDs), exencephaly, and disorganized neurocortex. In this study we further investigated the role of Rybp in neural differentiation by utilising wild type $\left(r y b p^{+/+}\right)$and rybp null mutant $\left(r y b p^{-/-}\right)$embryonic stem cells (ESCs) and tried to uncover underlying molecular events that are responsible for the observed phenotypic changes. We found that $r y b p$ null mutant ESCs formed less matured neurons, astrocytes, and oligodendrocytes from existing progenitors than wild type cells. Furthermore, lack of rybp coincided with altered gene expression of key neural markers including Pax6 and Plagll pinpointing a possible transcriptional circuit among these genes.

\section{Introduction}

Complex network of transcription factors (TFs) control the gene expression in the developing embryo that manages complex differentiation processes. TFs also have important roles in the adult life in maintaining the pattern of differentiated gene expression and several of them function in multisubunit protein complexes [1]. Rybp (Ring1 and Yyl Binding Protein, also known as Dedaf (Death Effector Domain-Associated Factor), Yeaf1 (Yy1 and E4tf1 Associated Factor 1); UniGene Mm.321633; MGI:1929059) is an evolutionarily conserved TF. It is also a member of the noncanonical mammalian polycomb repressive complex 1 (PRC1) $[2,3]$. PRCs are important regulators of organogenesis and cell lineage specification because they are able to maintain pluripotency and repress differentiation. Rybp also acts as a bridging factor between E2f and Yyl binding sites on target gene promoters, thus facilitating the formation of different multimeric TF complexes [4]. Complexes that form through these binding sites play important role in regulating cell proliferation and differentiation of multiple tissue lineages during early embryonic development. Rybp is also part of the BCOR complex (named after its BCL-6 corepressor subunit) [5], which plays important role in the differentiation of embryonic stem cells (ESCs) into ectoderm and mesoderm [6] and also is required for neurogenesis [7].

Our laboratory previously showed that Rybp is essential for early embryonic development, upregulated in certain cell types of the developing central nervous system (CNS), and that in a portion of the $r y b p^{+/-}$mice alterations in Rybp dosage resulted in striking neural tube defects (NTDs) and disorganization of the neocortex in vivo [8].

Here, we further characterized the role of Rybp in neural development. We utilized wild type $\left(r y b p^{+/+}\right)$and rybp null mutant $\left(r y b p^{-/-}\right)$ESCs, which lack functional Rybp protein, and differentiated them in vitro to neural lineages in order to reveal the function of Rybp in neural differentiation. Based on the in vivo evidences we hypothesized that in the absence of Rybp ESCs cannot undergo neural differentiation or have impaired neural differentiation ability. We showed impairment in neural lineage entry of ESCs in the lack of functional Rybp during in vitro neural differentiation. When analyzed in depth, the tumor suppressor Plagll (Pleomorphic Adenoma Gene-like 1 also known as Zacl (Zinc Finger Protein Regulating Apoptosis and Cell-cycle Arrest) 
and Lot1 (Lost on Transformation 1) UniGene Mm.287857; MGI:1100874) was one of the most downregulated genes in the Rybp deficient cells. Since Plagll is a critical regulator of neural differentiation $[9,10]$ our results suggest that Plagl1 may, at least partially, mediate the effects of Rybp during neural differentiation.

\section{Materials and Methods}

2.1. Chemicals. All chemicals were purchased from SigmaAldrich (St. Louis, MO, USA), and culture media reagents were purchased from Invitrogen Life Technologies (Carlsbad, CA, USA), unless stated otherwise.

2.2. Cell Lines and Culture Condition. Mouse (129SV/Ola) R1 [11] (hereafter mentioned as $r y b p^{+/+}$, control, or wild type) and D11 [8] (hereafter mentioned as $r y b p^{-/-}$or null mutant) (Figure S1 in Supplementary Material available online at http://dx.doi.org/10.1155/2015/4034620) ESCs were thawed on mitomycin $\mathrm{C}$ inactivated mouse embryonic fibroblast (MEF) layer and cultured on gelatin coated tissue culture plates as described [12]. The cells were maintained in ES medium: Dulbecco's Modified Eagle's medium (DMEM (1x) + GlutaMAX-I Dulbecco's Modified Eagle Medium, Gibco, REF 31966-021) contained 15\% (vol/vol) fetal bovine serum (Gemini Stasis Stem Cell Qualified FBS, West Sacramento, CA, USA, Cat. Number 100-125), 0.1 mM nonessential amino acids (MEM Nonessential Amino Acids (100x), PAA, Cat. Number M11-003), $0.1 \mathrm{mM} \beta$-mercaptoethanol (2-Mercaptoethanol, Gibco, REF 31350-010), $50 \mathrm{U} / \mathrm{mL}$ penicillin/streptomycin (Penicillin/Streptomycin (100x), PAA, Cat. Number P11-010), and $1000 \mathrm{U} / \mathrm{mL}$ Leukemia Inhibitory Factor (LIF, ESGRO, Chemicon/Millipore, Billerica, MA, USA). The cells were passaged prior to reaching $70 \%$ confluency (approximately every 1-2 days). ESCs were cultured on gelatin coated dishes for at least two passages prior to differentiation to deplete potentially present MEF cells from the ESC culture. Cells were cultured in a humidified atmosphere containing $5 \% \mathrm{CO}_{2}$ at $37^{\circ} \mathrm{C}$. ES medium was changed daily.

2.3. Induction of Neural Differentiation by Retinoic Acid. ESCs were induced to differentiate into neuronal lineages as previously described, with some modifications (Figure 1(a)) [13]. In brief, mouse ESCs were harvested as single cell suspension using $0.05 \%$ (wt/vol) trypsin (Trypsin-EDTA (1x) $0.05 \% / 0.02 \%$ in D-PBS, PAA, Cat. Number L15-004) and then seeded at a density of $4.5 \times 10^{5}$ cells $/ \mathrm{mL}$ in ES medium without LIF into $100 \mathrm{~mm}^{2}$ bacteriological dishes where cell attachment was prevented. ESCs were allowed to aggregate in suspension and form embryoid bodies (EBs) for 8 days. Medium was changed on every second day during differentiation unless stated otherwise. On the 4th day of EB formation $5 \mu \mathrm{M}$ all-trans retinoic acid (RA) (retinoic acid, Sigma, Cat. Number R2625-100MG) was added to the medium and EBs were cultured for a further 4 days in the presence of RA. Thereafter, 8-day-old EBs were dissociated using trypsin and plated onto poly-L-ornithine (Poly-L-Ornithine $0.01 \%$, Sigma, Cat. Number P4957) and laminin (Laminin from
Engelbreth-Holm-Swarm murine sarcoma basement membrane, Sigma, Cat. Number L2020-1MG) coated dishes at a density of $3 \times 10^{5}$ cells $/ \mathrm{cm}^{2}$ in DMEM/F-12 medium containing $3 \mathrm{mg} / \mathrm{mL}$ of D-(+)-glucose, $3 \mathrm{mg} / \mathrm{mL}$ AlbuMax I, $50 \mathrm{U} / \mathrm{mL}$ penicillin/streptomycin, and $1 \%$ (vol/vol) N-2 supplement (N-2 Supplement (100x), Gibco, Cat. Number 17502-048), and $10 \mathrm{ng} / \mathrm{mL}$ recombinant human bFGF (Fibroblast Growth Factor Basic, human, Sigma, Cat. Number F0291-25UG); the medium was changed 24 hours later. Two days after cells were plated, the medium was changed to DMEM/F12:Neuronal Base Medium (Neuronal Base Medium For Neuronal Cells, PAA, Cat. Number U15-023) (1:1), 1 mM GlutaMax, 3 mg/mL AlbuMax I, $50 \mathrm{U} / \mathrm{mL}$ penicillin/streptomycin, $0.5 \%$ ( $\mathrm{vol} / \mathrm{vol}$ ) N-2 Supplement, and $1 \%$ (vol/vol) B-27 supplement (B-27 Supplement (50x), Gibco, Cat. Number 17504-044). The cells were harvested for further analyses on different time points of neural differentiation: days $0,3,7,10$, and 14 (labeled as $\mathrm{d} 0$, $\mathrm{d} 3, \mathrm{~d} 7, \mathrm{~d} 10$, and d14). On d10 and d14 the differentiated cells were also stained with cresyl violet in order to visualize the cell colonies and morphology of the cells. The images of the ESC cultures, EBs, and stained neural culture were obtained using Olympus cellR microscope (Olympus Corporation, Japan).

2.4. Quantitative Real-Time PCR ( $q R T-P C R)$. For quantitation of mRNA levels during the in vitro differentiation quantitative real-time PCR (qRT-PCR) assays were performed. Total RNA was extracted from the harvested cells using Qiagen RNeasy Plus Mini Kit (Qiagen, Cat. Number 74134 Hilden, Germany) according to the manufacturer's instructions. cDNA synthesis was achieved with the isolated RNA using Applied Biosystems High capacity cDNA Reverse Transcription Kit (Invitrogen Life Technologies, Cat. Number 4368814 Carlsbad, CA, USA) according to the manufacturer's instructions.

qRT-PCR was performed in SYBR Green master mix (SYBR Select Master Mix for CFX, Applied Biosystems, REF 4472942) using Bioer LineGeneK Real-time PCR System (Bioer, China). Relative gene expression changes were quantified using the $\Delta \Delta \mathrm{Ct}$ method. The threshold cycle $(\mathrm{Ct})$ values for each gene were normalized to expression level of Hprt, as internal control. To calculate fold change, the values were compared to undifferentiated samples $\left(\mathrm{d} 0, r y b p^{+/+}\right)$. The primers used in this study were listed in Supplementary Table 1 .

2.5. Immunocytochemistry Analysis. For immunofluorescence staining of the cells, they were plated onto coverslips, differentiated into neuronal lineages as described above, and fixed with $4 \%(\mathrm{v} / \mathrm{v})$ paraformaldehyde (PFA) for $20 \mathrm{~min}$ at room temperature (RT). After permeabilization in $0.2 \%$ Triton X-100 (Triton X-100, Sigma, Cat. Number T8787-250ML) in Phosphate Buffered Saline (PBS, DPBS (1x) Dulbecco's Phosphate Buffered Saline, Gibco, REF 14190-094) for $20 \mathrm{~min}$ at RT, cells were blocked in 5\% Bovine Serum Albumin (BSA) (Albumin from bovine serum, Sigma, Cat. Number A7906) in PBS for $1 \mathrm{~h}$ at RT and then sequentially incubated with the following primary antibody in 5\% BSA overnight at 


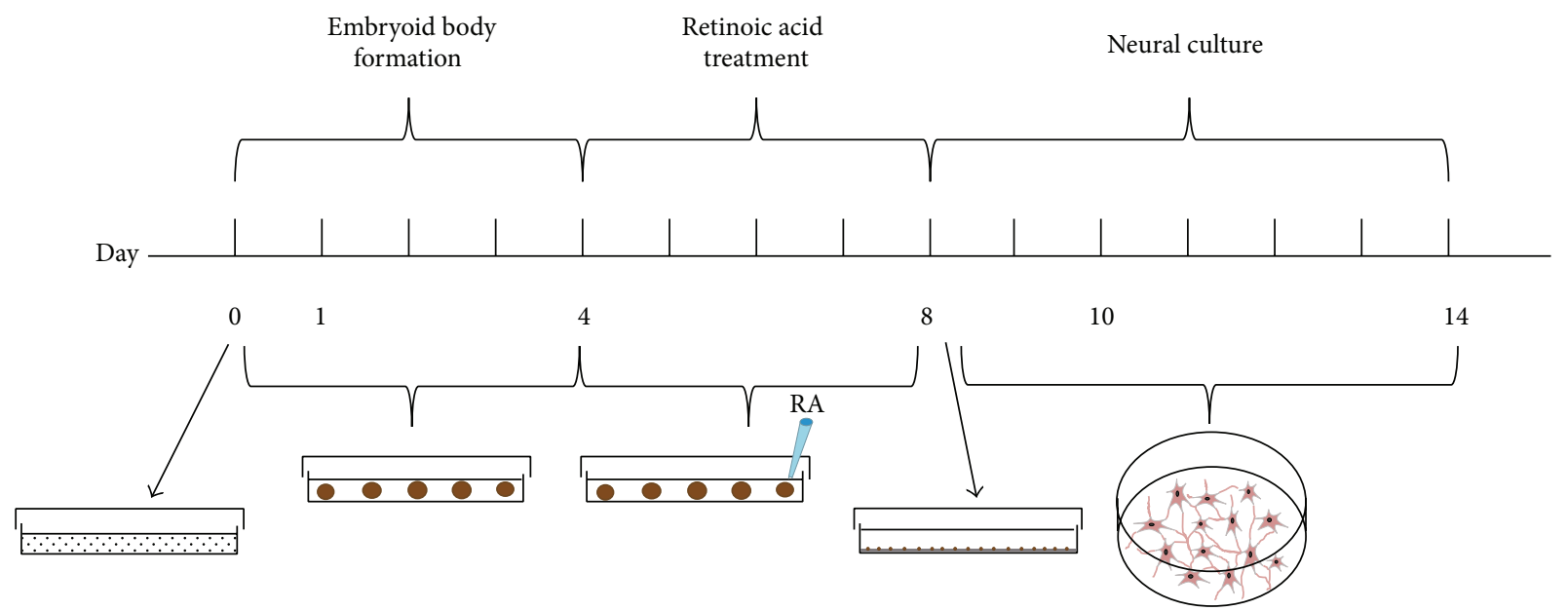

(a)
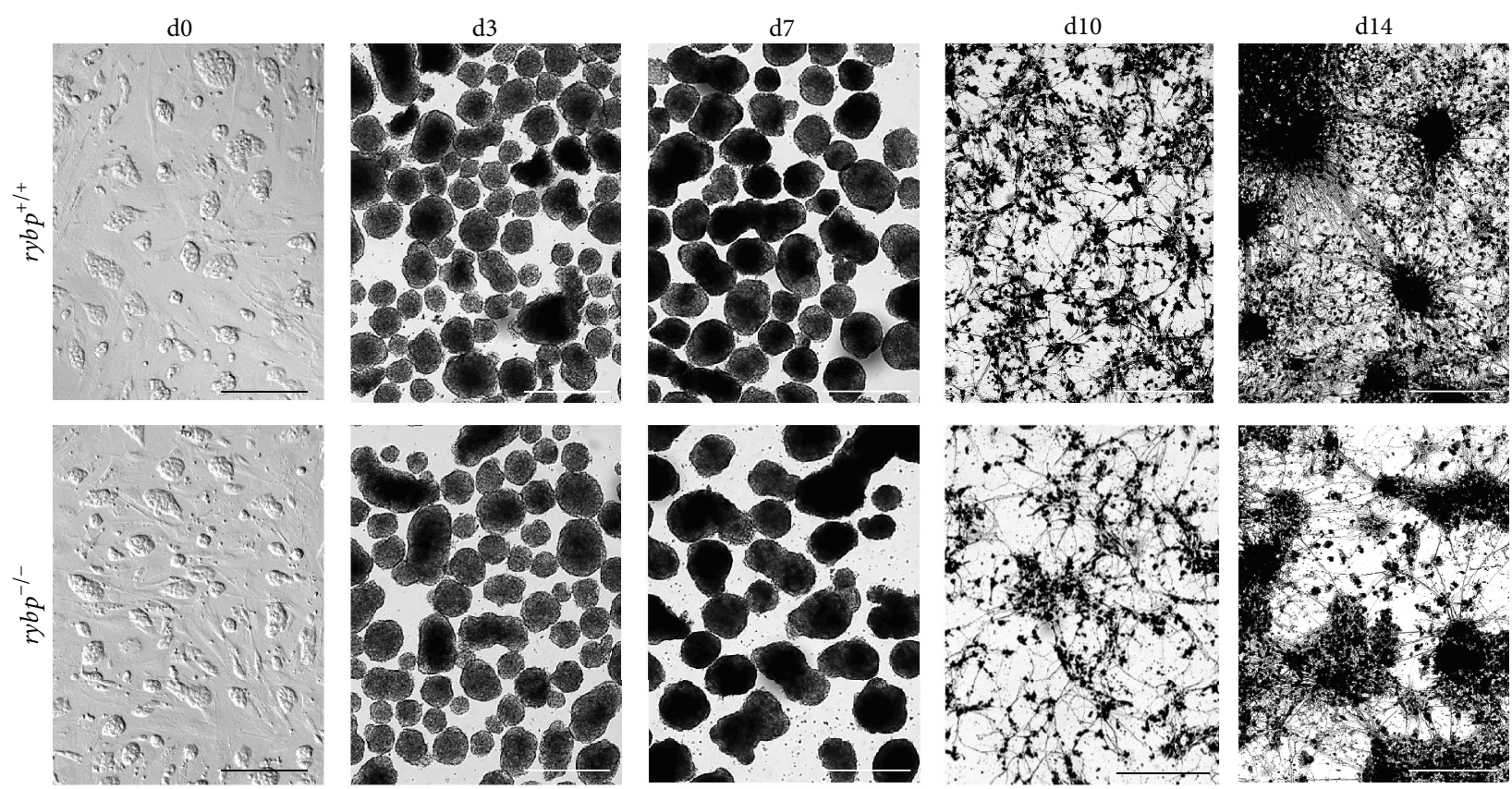

(b)

FIGURE 1: Morphological changes of $r y b p^{+/+}$and $r y b p^{-/-}$cells through in vitro neural differentiation. (a) Schematic illustration of in vitro neural differentiation as described previously by Bibel et al. (b) The rybp ${ }^{-/-}$ESCs display the same morphology in culture as the wild type (d0) and also form EBs (d3, d7). There is no noticeable difference between the two cell lines. After the plating (d10, d14) the $r y b p^{-/-}$cells grew less organized neural network than the wild type. Magnifications are $4 \mathrm{x}(\mathrm{d} 3, \mathrm{~d} 7)$ and $10 \mathrm{x}(\mathrm{d} 0, \mathrm{~d} 10, \mathrm{~d} 14)$. Scale bars represent 500 $\mu \mathrm{m}(\mathrm{d} 3$, $\mathrm{d} 7)$ and $200 \mu \mathrm{m}(\mathrm{d} 0, \mathrm{~d} 10, \mathrm{~d} 14)$.

$4^{\circ} \mathrm{C}$ : Nestin (Rat-401, Hybridoma Bank, Iowa, USA, 1:100), Pax6 (Pax6, Hybridoma Bank, Iowa, USA, 1:100), Tuj1 (Neuronal Class III $\beta$-Tubulin Polyclonal Antibody; Covance, Cat. Number PRB-435P, 1:2500), Gfap (Monoclonal Anti-Glial Fibrillary Acidic Protein Clone G-A-5, Sigma, Cat. Number G3893, 1:400), and Plagl1 (Zac1 (M-300), Santa Cruz Biotechnology, Cat. Number sc-22812, 1:1000). The cells were washed 5 times with PBS and incubated with fluorescent-labeled secondary antibodies (Alexa Fluor 647 Donkey-Anti-Mouse, Invitrogen, Cat. Number A-31571; Alexa Fluor 647 Goat-Anti-Rabbit, Invitrogen, Cat. Number
A-21244; Alexa Fluor 488 Goat-Anti-Mouse, Invitrogen, Cat. Number A-10667) for $1 \mathrm{~h}$ at RT. Then the cells were washed 3 times with PBS. The cells were rinsed in $4^{\prime}, 6$-diamidino2-phenylindole (DAPI; Vector Laboratories, Cat. Number H1200) for $20 \mathrm{~min}$, washed 2 times with PBS, and mounted in $50 \%$ glycerol. The images were obtained using Olympus LSM confocal microscope (Olympus Corporation, Japan).

2.6. Statistical Analysis. All experiments were repeated three times. Experiments were evaluated with SPSS/PC+ version 17 program (SPSS, Chicago, IL) by using $t$-test type 3. Means 
are standard deviation. Values of $P<0.05$ were accepted as significant $\left({ }^{*} P<0.05 ;{ }^{* *} P<0.01 ;{ }^{* *} P<0.001\right)$.

\section{Results}

3.1. Neural Cell Culture Differentiated from rybp ${ }^{-/-}$ESCs Exhibit Different Morphology than Wild Type. In order to investigate the possible molecular mechanisms underlying the in vivo neural phenotypes of the $r y b p^{+/-}$mice we took advantage of the ESC based in vitro neural differentiation system. Thus, we adopted the protocol by Bibel et al. [13] in order to differentiate $r y b p^{+/+}$[11] and $r y b p^{-/-}$[8] ESCs lacking functional Rybp protein product towards neural cell lineages (Figure 1(a)). In brief, suspension cultures were initiated using $4.5 \times 10^{5}$ cells $/ \mathrm{mL}$ initial seeding density and were kept in suspension for 8 days to form EBs. RA was added to the suspension cultures on $\mathrm{d} 4$ and EBs were kept in RA supplemented medium until trypsinization on $\mathrm{d} 8$ and then seeded on poly-L-ornithine/laminin coated surfaces and differentiated further for another week. Samples for analysis were taken at $\mathrm{d} 0, \mathrm{~d} 3, \mathrm{~d} 7, \mathrm{~d} 10$, and $\mathrm{d} 14$ and processed as required. $R y b p^{-/-}$ESCs display similar morphology in culture as the control cell line (Figure 1(b) d0) and by d7 EBs grew larger compared to $\mathrm{d} 3$ in both cell lines (Figure 1(b), $\mathrm{d} 3, \mathrm{~d} 7)$ suggesting that $r y b p^{-1-}$ cells are not compromised in their ability to form EBs and proliferate. As expected, after plating EBs on poly-L-ornithine and laminin coated surfaces, the wild type cells exhibited typical neuronal morphology and the cells grew axon-like outgrowth, connected to each other, and organized in a complex network consisting of heterogeneous cell population (Figure 1(b) d10, d14). However, $r y b p^{-/-}$cells grew less neurite processes and their organization into network was less extended in comparison to the wild type. This phenotype was independent from the initial cell density (Figure 1(b), d10, d14; data not shown). The gross morphology of the cells suggests that neuronal differentiation was affected by absence of rybp.

3.2. Expression of Pluripotency Markers in the Lack of Rybp during Neural Differentiation. To uncover underlying mRNA expression changes during in vitro neural differentiation we evaluated gene expression levels by qRT-PCR. First, we confirmed that the $r y b p^{-/-}$cells do not produce functional protein (Figure 2(a)). Then we analyzed the expression of pluripotency markers in both cell lines. Incomplete silencing of the pluripotency genes during differentiation inhibits neural differentiation. The analysis revealed that the expression of examined pluripotency markers Oct 4 and Nanog was progressively downregulated in both cell lines by differentiation (Figures 2(b) and 2(c)) and there were no significant changes in the kinetics of pluripotency gene expression between the $r y b p^{+/+}$and $r y b p^{-/-}$cells.

Sox 2 together with Oct4 and Nanog maintains pluripotency in stem cells and neural progenitors (NPCs) and, in addition, Sox 2 is also important in the induction of neuroectoderm $[14,15]$. The relative expression levels of Sox 2 in both cell lines are similar with the exception of $\mathrm{d} 14$ when the level of Sox 2 is diminished in the rybp null mutant whilst it stays high in the wild type (Figure $2(\mathrm{~d})$ ). This suggests that the differentiation ability of rybp null stem cells to NPCs or maintaining the characteristics of NPCs might be compromised. These results suggested that the silencing of key pluripotency genes exhibits similar kinetics with the exception of Sox2, which in the rybp null mutants drastically declines by $\mathrm{d} 14$.

3.3. Expression of Key Neural Markers in the Lack of Rybp during Neural Differentiation. After examination of the key pluripotency markers we analyzed the relative gene expression of key neural markers (e.g., Nestin, Pax6, NeuroD1, Tubb3, NeuN, Gfap, and Olig2) in both cell lines to gain information about the kinetics of neural differentiation.

Nestin is a widely employed marker of multipotent neural stem cells (NSCs) [16]. Once the cells become differentiated, Nestin expression is downregulated both in vivo and in vitro [17]. As expected, at the time of neural induction (d7, RA treatment) Nestin is strongly upregulated at $\mathrm{d} 7$ in both cell lines (Figure 3(a)). Nestin expression increased further after plating of the cells (d10) and its level decreased only at later phases of neural differentiation (d14) in both cell lines (Figure 3(a)). Notably, Nestin expression was more robust in the $r y b p^{-/-}$cell line compared to the $r y b p^{+/+}$at $\mathrm{d} 10$. Immunocytochemistry with Nestin antibody confirmed the presence of NPCs in both cell lines with stronger expression in the $r y b p^{-/-}$cells at d10 (Figure 4(a)). By the endpoint of in vitro neural differentiation (d14) the number of Nestin expressing cells was reduced in both cell lines (Figure 4(a); Figure S2(a) and (b)). These results suggest that early neural processes take place in a greater extent in the absence of functional Rybp.

Paired Box 6 (Pax6) gene is required for the initiation of neural differentiation and described as an essential factor for normal eye development as well [18]. Relative gene expression analysis revealed that Pax6 is upregulated after the RA treatment (Figure 3(b) from d7) and its level decreased at later time points of neural differentiation (d14) in the wild type cells. Expression of Pax6 was higher after neuroectodermal induction in the $r y b p^{-/-}$cells compared to the wild type (Figure 3(b) from d7). Pax6 immunostaining visualizes the distribution of Pax6 positive cells in the wild type and mutant neural cell cultures (Figure 4(b)). The Pax6 signal was stronger in the mutant cultures in all examined time points (Figure 4(b); Figure S2(c) and (d)). In both cell lines the number of Pax6 positive cells is higher at d10 when early differentiation events take place. These results correlate with the data of Pax6 qRT-PCR analysis and indicate an abundance of Pax6 positive cell population in the rybp null mutants.

Neurogenic Differentiation 1 (NeuroD1) is a TF, which is essential for terminal neuronal commitment of maturing neurons [19]. NeuroD1 drives premature differentiation of neuronal precursors into mature neurons. Relative gene expression analysis by qRT-PCR showed that the NeuroD1 is mildly expressed after RA treatment (d7) in both cell lines (Figure 3(c)). The expression level of NeuroD1 is significantly higher at early stage (d10) in the mutant cell line compared to the wild type. The expression of NeuroD1 decreased by 


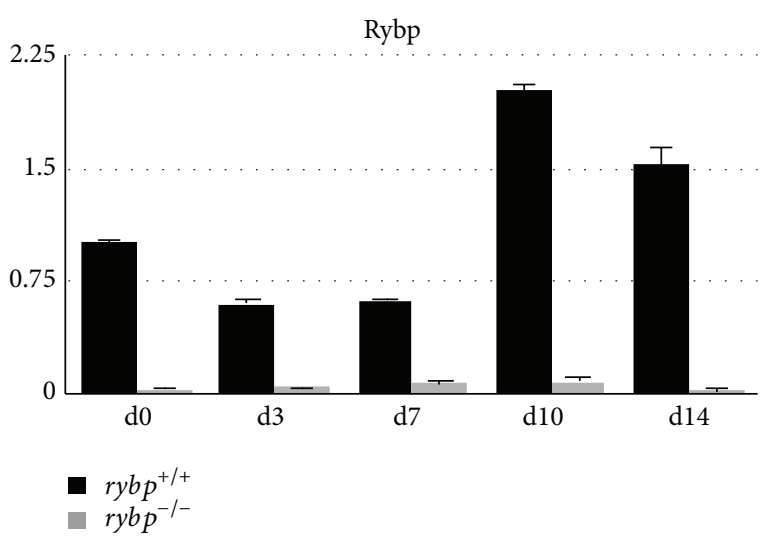

(a)

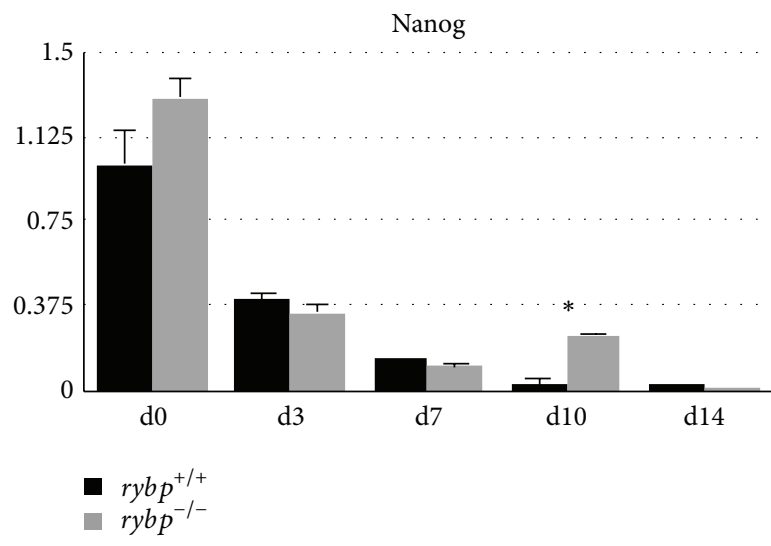

(c)

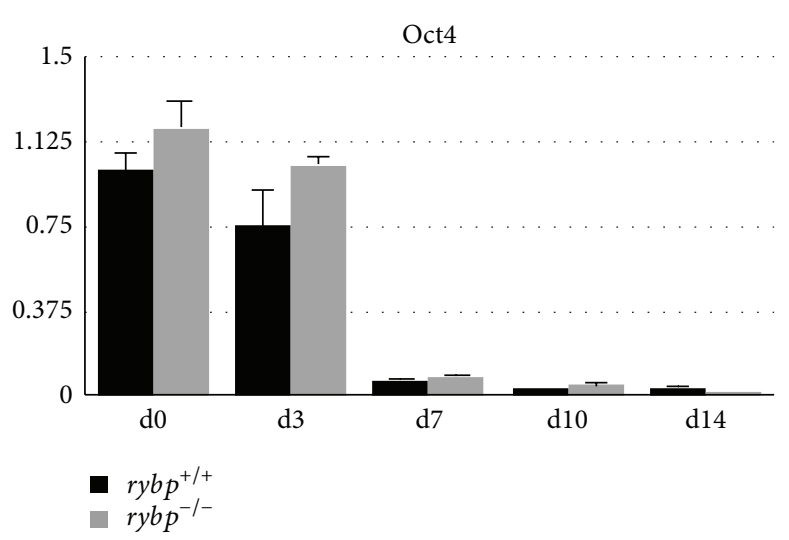

(b)

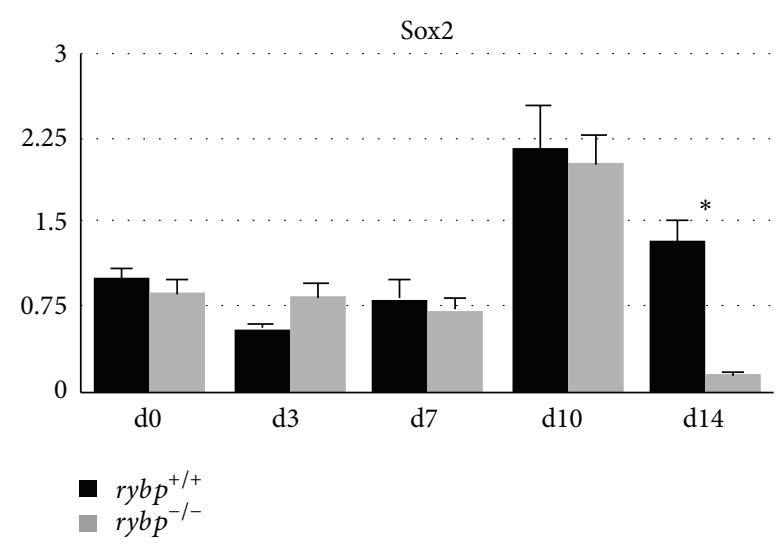

(d)

FIGURE 2: In the lack of Rybp there is no change in silencing of key pluripotency markers (Oct4, Nanog) during in vitro neural differentiation. Relative gene expressions of Rybp (a), Oct4 (b), Nanog (c), and Sox2 (d) were analyzed by qRT-PCR. For the analysis RNA was extracted and reverse-transcribed from differentiated neural cell culture generated from $r y b p^{+/+}$and $r y b p^{-/-}$ESCs. Samples are collected at days $0,3,7,10$, and 14 of differentiation. The expression of the indicated markers was normalized to Hprt expression, which was used as an internal control. Means are standard deviation. Values of $P<0.05$ were accepted as significant $\left({ }^{*} P<0.05 ;{ }^{* *} P<0.01 ;{ }^{* * *} P<0.001\right)$. Statistical method: $t$ test type 3.

the end of differentiation (d14) in the rybp ${ }^{-/-}$cells whilst there is only a minor decrease in its level in the $r y b p^{+/+}$ cells. At d14, NeuroD1 expression is higher in the wild type cells compared to the mutants. This also confirms that the characteristics of NPCs are altered in the rybp null mutants: at the beginning/mid-phase of differentiation ( $\mathrm{d} 7$ and 10$)$ the premature differentiation of NPCs is accelerated but by the end of differentiation (d14) it is attenuated.

Class III Beta-Tubulin (Tubb3) plays a critical role in proper axon guidance, maintenance, and axonal transport $[20,21]$ and also is expressed in postmitotic phase of differentiating neurons [22]. Relative gene expression analysis by qRT-PCR showed that Tubb3 expression is elevated at early stage (d10) in both cell lines but its expression declines in the rybp ${ }^{-1-}$ cells at later stage of neural differentiation (d14) while its level still remains high in the wild type (Figure 3(d)). In order to visualize ongoing neural differentiation spatiotemporally we stained the cells with Tuj1 antibody, which marks Tubb3 positive cells. The assessment of Tuj1 staining (Figure 4(c); Figure S2(e) and (f)) showed that neurite processes and axon-like structures start to develop in both cell lines however in the $r y b p^{+/+}$cells exhibit a complex and dense network of outgrowth compared to the mutants. Notably, Tubb3 also is expressed in the soma, around the nucleus in $r y b p^{+/+}$cells, while in the $r y b p^{-/-}$ cells this staining was less visible. The reduced density of nerve fibers by ICC in the mutant cell line was consistent with the data on diminished amount of nerve bundles on Tubb3 by qRT-PCR analyses. These data suggest that a normal level of Rybp is important for the proper development of neurons.

In order to ascertain the presence of mature neurons in our cell cultures we assessed the relative gene expression changes of postmitotic neuronal marker NeuN (also known as Rbfox3). NeuN marks the nuclei of maturing and differentiated neurons [23]. As expected, qRT-PCR analysis showed that NeuN was abundantly expressed in the plated wild type neural cultures (d10, d14) but its level stayed constantly low in the mutants (Figure 3(e)). This indicates that much less mature neurons formed in the rybp null mutant culture (d10, d14) and further confirms the compromised differentiation ability of rybp null NPCs. 


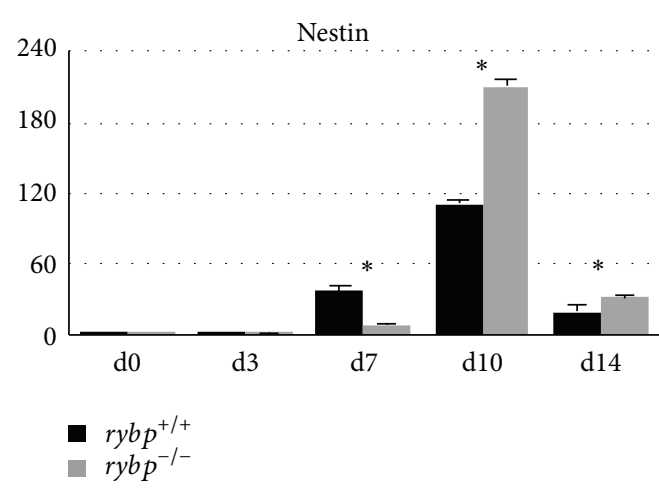

(a)

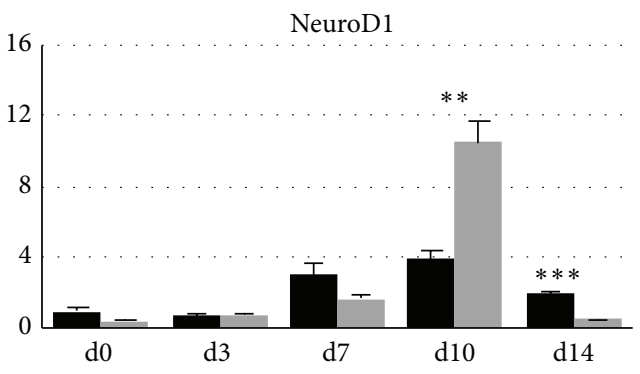

- $r y b p^{+/+}$

- $r y b p^{-1-}$

(c)

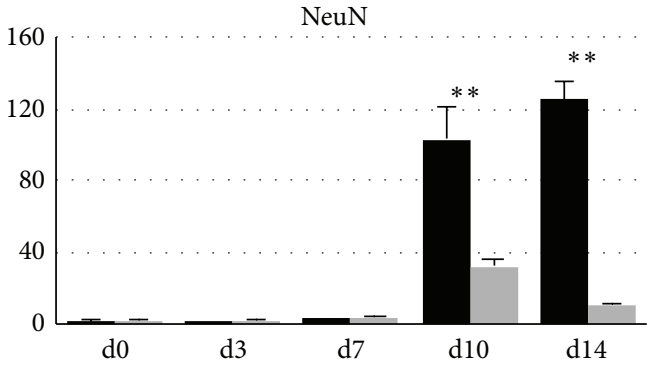

- $r y b p^{+/+}$

$r y b p^{-1-}$

(e)

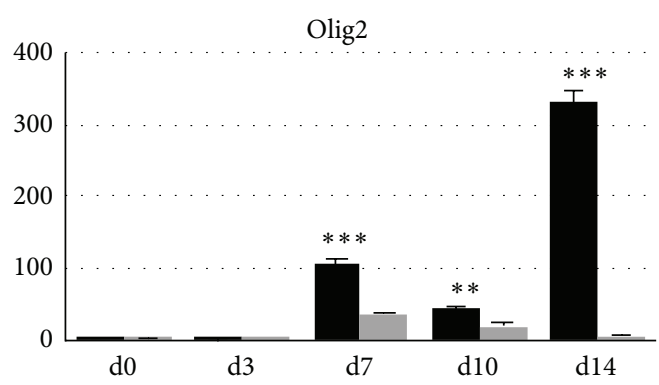

- $r y b p^{+/+}$

- $r y b p^{-1-}$

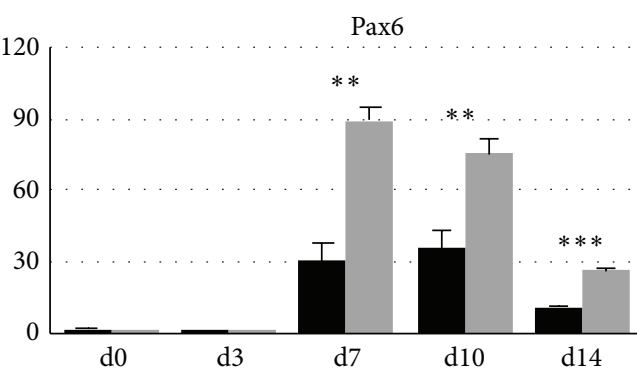

- $r y b p^{+/+}$

- rybp

(b)

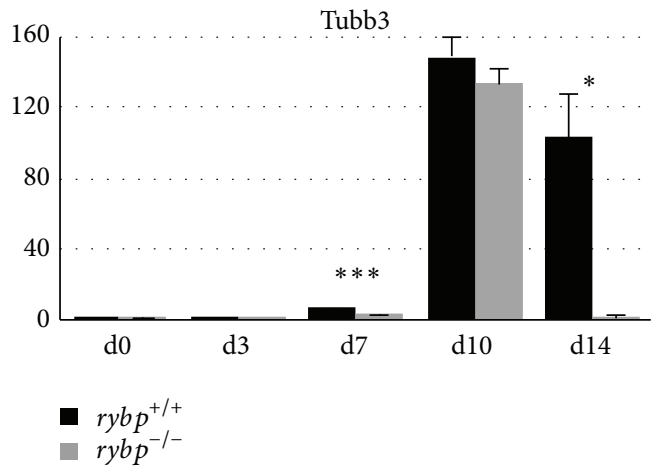

(d)

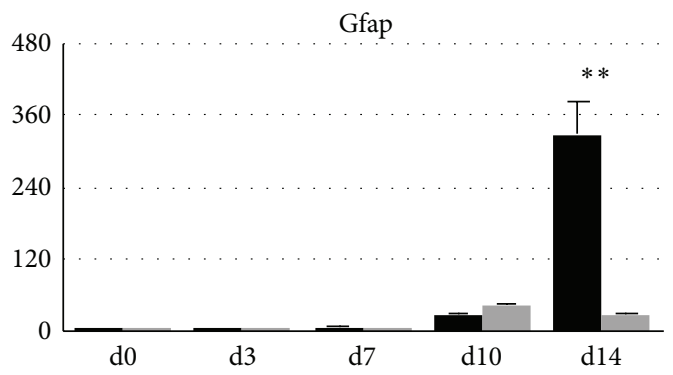

- $r y b p^{+/+}$

- $r y b p^{-1-}$

(f)

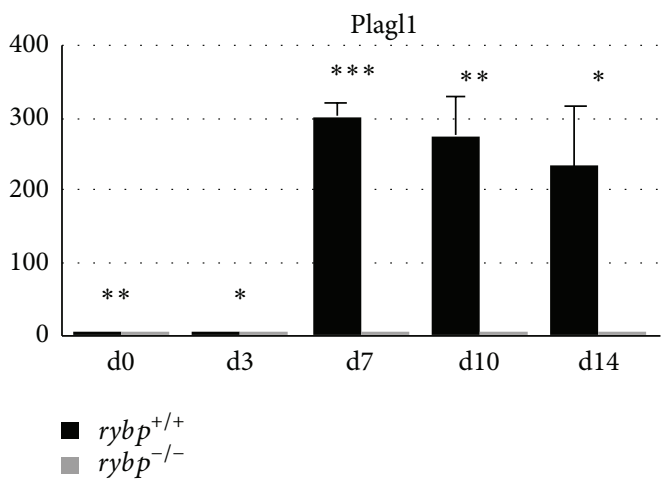

(h)

Figure 3: Neural markers (Nestin (a), Pax6 (b), NeuroD1 (c), Tubb3 (d), NeuN (e), Gfap (f), and Olig2 (g)) and transcription factor, Plagl1 (h), exhibit altered expression in the lack of Rybp during in vitro neural differentiation. Relative gene expression of key neural markers was analyzed with qRT-PCR. For the analysis RNA was extracted and reverse-transcribed from differentiated neural cell culture generated from $r y b p^{+/+}$and $r y b p^{-1-}$ ESCs. Samples are collected at days $0,3,7,10$, and 14 of differentiation. The expressions of the indicated markers were normalized to Hprt expression, which was used as an internal control. Means are standard deviation. Values of $P<0.05$ were accepted as significant $\left({ }^{*} P<0.05 ;{ }^{* *} P<0.01 ;{ }^{* * *} P<0.001\right)$. Statistical method: $t$ test type 3 . 

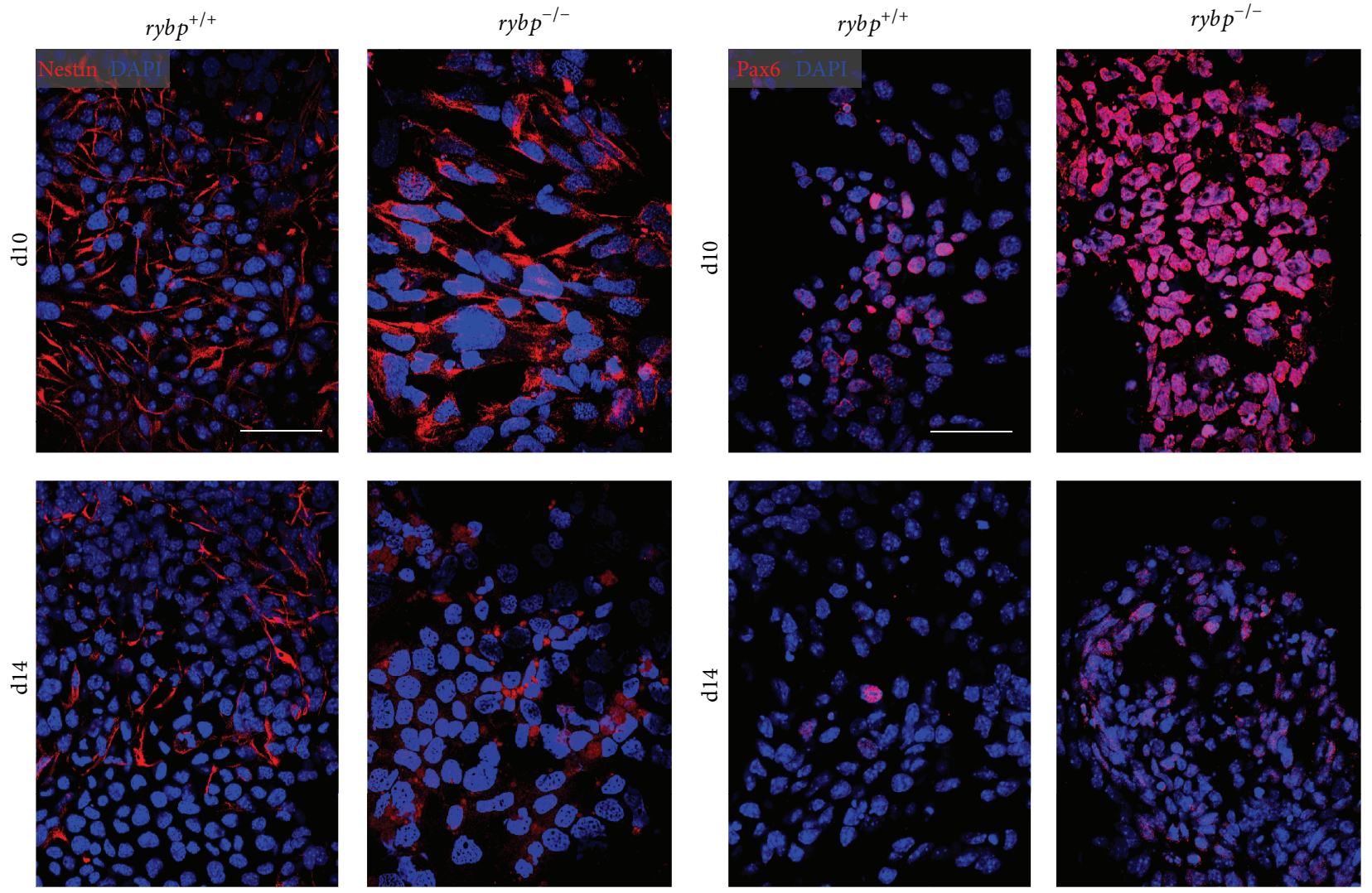

(a)

$r y b p^{-1-}$
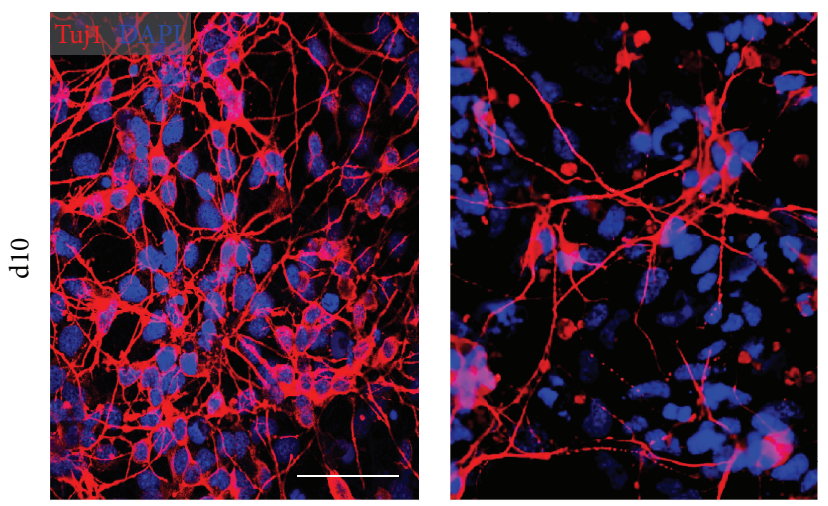

$r y b p^{+1+}$

(b)

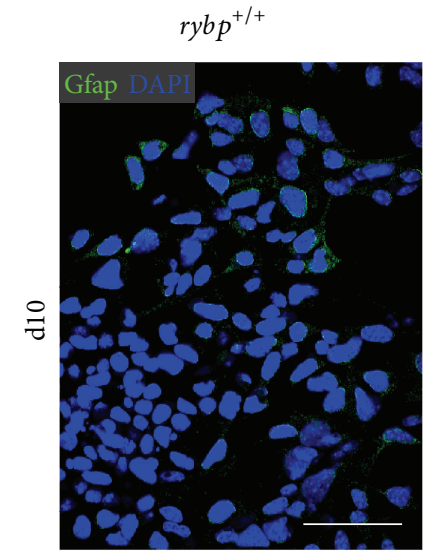

$r y b p^{-/-}$
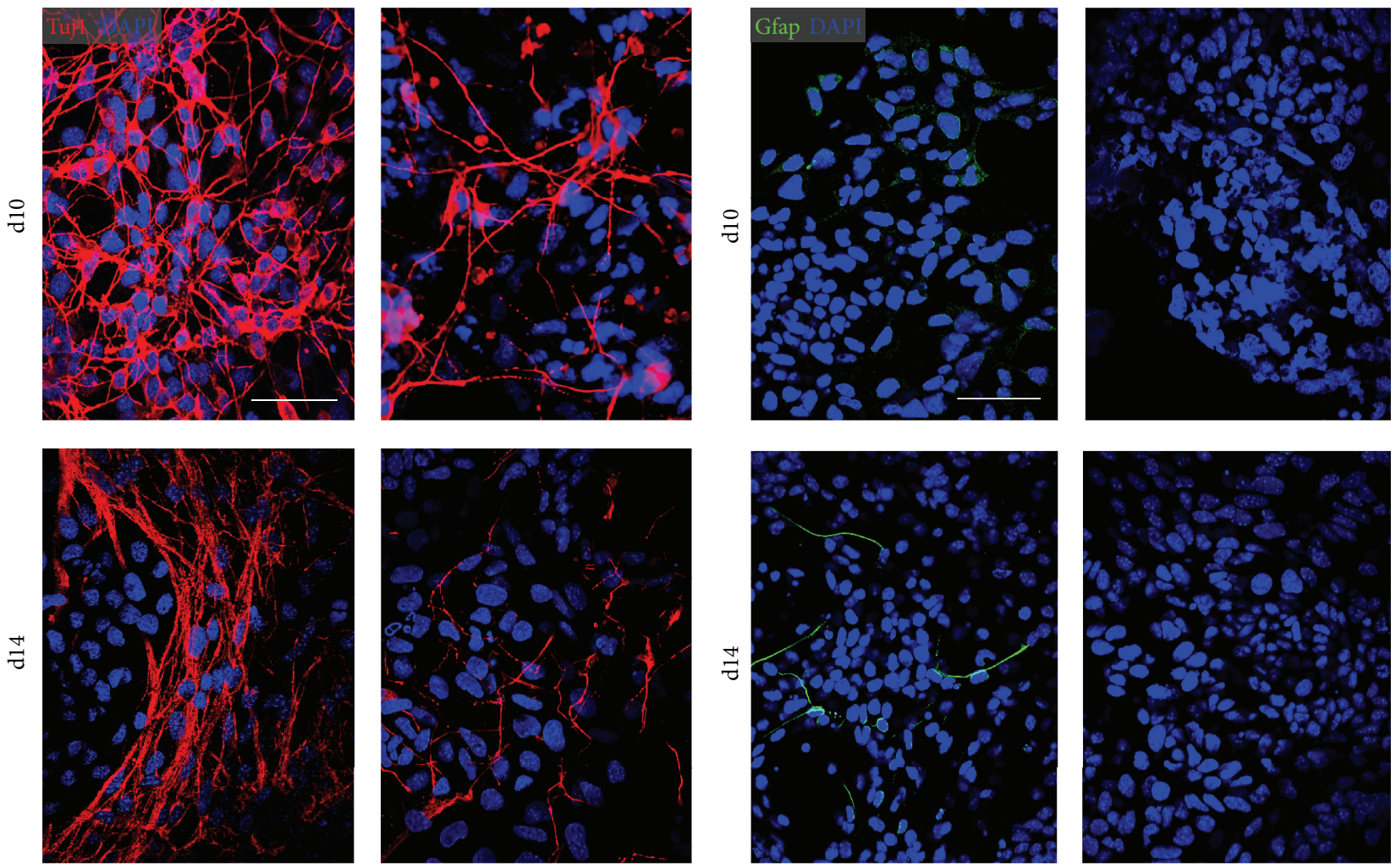

(c)

Figure 4: Continued. 

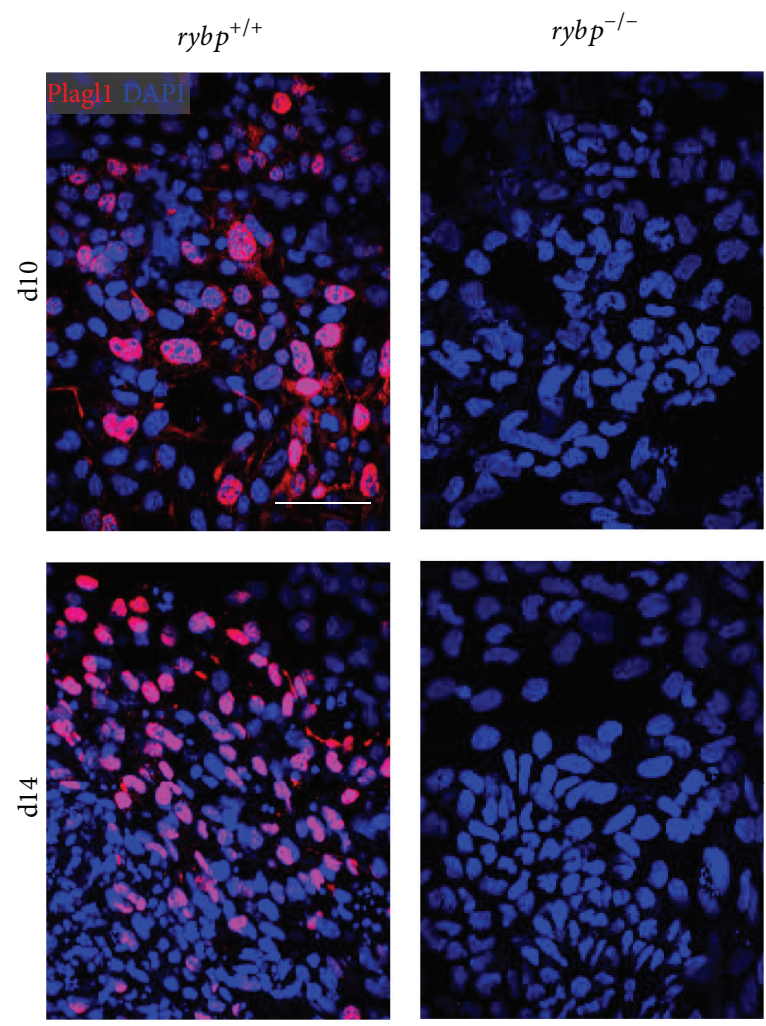

(e)

FIGURE 4: Rybp deficient cells show impaired protein expression of neural markers during in vitro neural differentiation. Immunocytochemical analysis of in vitro differentiated neural cultures shows that there are more Nestin (a) and Pax6 (b) and less Tuj1 (c) are visible in the rybp null mutant neural cell cultures by d10. Nestin and Tuj1 staining are reduced in the $r y b p^{-1-}$ cell culture by d14 compared to wild type, which indicates possible defects in the late neural processes. Immunostaining of astrocyte marker, Gfap (d), shows a small amount of astrocyte-like cells in wild type culture, which is absent in the mutant. Immunocytochemistry with antibody against Plagll (e) reveals that Plagl1 is expressed in the nucleus of $r y b p^{+/+}$cells but it is absent in $r y b p^{-/-}$cells. Magnification is 60x. Scale bars represent $60 \mu \mathrm{m}$.

This observation tempted us to speculate whether this defect is specific for neurons or other cell types like astrocytes and oligodendrocytes are also affected in the absence of Rybp. Therefore we next analyzed whether cells lacking functional Rybp are able to generate astrocytes as well. In order to do so, we have performed relative gene expression analysis by qRT-PCR in both cell lines for the intermediate filament Glial Fibrillary Acidic Protein (Gfap), which is a commonly accepted marker of radial glia and astrocytes [24]. Our analysis revealed that the level of Gfap is elevated over $300 \mathrm{x}$ in the wild type cells (Figure 3(f) d14). In comparison its level stayed low in the rybp null mutants (Figure 3(f) d14). We also analyzed the spatial distribution of Gfap by immunostaining and found that there were no Gfap positive cells in the mutant neural cultures (Figure 4(d); Figure S2(g) and $(\mathrm{h}))$. This suggests that the astrocyte differentiation is defective in the mutant cells.

We also investigated if the absence of Rybp has influence on other types of glial cells or it is specific for astrocytes. For this purpose, we measured the relative expression level of Oligodendrocyte Lineage Transcription Factor 2 (Olig2) by qRT-PCR. Olig2 is a marker gene for oligodendrocytes [25-27]. Oligodendrocyte differentiation normally starts by $\mathrm{d} 7$ and peaks by $\mathrm{d} 14$ (Figure $3(\mathrm{~g}) r y b p^{+/+}$cells). In contrast, the $r y b p^{-/-}$cells expressed 60x less Olig2 mRNAs at d14 compared to the wild type (Figure $3(\mathrm{~g})$ ). This demonstrates that oligodendrocyte differentiation is also impaired in the absence of Rybp.

3.4. Plagl1 Is a Downstream Target of Rybp during In Vitro Neural Differentiation. Previously, we have shown that Plagll is a candidate downstream gene of Rybp during in vitro cardiac differentiation of mouse embryonic stem cells [28]. Plagll has dual role; it is an important gene for cardiac development and it has also crucial role in neural development [10, 29]. Moreover, lack of Plagl1 in mouse models caused marked defects in CNS development (e.g., reduced size of cerebellum, reduced number of mature neurons) [9], which are similar to the phenotype of the $r y b p^{+/-}$mice (see above, Section 1) [8].

Therefore, next we have tested whether the differences in mRNA expression are also sustained (or changed) during neural differentiation between the wild type and rybp null mutant cell lines. Gene expression analysis (Figure 3(h)) revealed that Plagll is strongly induced $(\sim 300 \mathrm{x})$ after the RA treatment (d7) during in vitro neural differentiation in the wild type cells and remained high until the end of 
differentiation (d14). However in the rybp ${ }^{-/-}$cells Plagll was not induced and showed complete deficiency.

After this, we wanted to test whether the difference in Plagll mRNA induction is also sustained at protein level. In order to visualize the spatiotemporal distribution of Plagll throughout the differentiation process we performed immunocytochemistry of in vitro neural cultures with antibody against the Plagll protein (Figure 4(e); Figure S2(i) and (j)). This confirmed that Plagll is visible in the nuclei of the wild type cells (Figure 4(e), wild type cells at d10 and d14) while in the rybp ${ }^{-/-}$cells there is a complete lack of Plagll staining. These results showed that Plagll induction is impaired in $r y b p^{-1-}$ cells during the entire course of neural differentiation.

\section{Discussion}

Current work investigates the possible underlying molecular mechanisms responsible for the previously described phenotype of the rybp heterozygous mouse models [8]. Considerable attention has focused on the search for downstream target genes that may mediate the biological effect of Rybp in neural lineage commitment. Our study showed that the development of both neuronal and glial lineages is defective in the rybp null ESCs derivatives. Furthermore, our study establishes that the process of differentiation towards mature neural cell types rather than to a specific lineage is impaired in the lack of Rybp.

The contribution of $r y b p^{-/-}$ESCs to neural lineage commitment is particularly interesting since in vivo evidence has been already provided that Rybp is important for neural development and it is broadly expressed in different cell types of the CNS. Moreover misexpression of Rybp was shown in glioblastomas and other types of tumors [30].

Our results showed that the properties of rybp null NPCs are compromised: rybp null NPCs express Pax6, Nestin, and NeuroD1 in excess in comparison to the wild type ones. Pax6 is one of the key transcriptional factors [31], whose level needs to be upregulated at the beginning of neural development since Pax6 plays important role in establishing neuronal progenitor pool during the vertebrate nervous system development [32] (Figure 5). At the same time downregulation of Pax6 is also necessary for the forthcoming, late neural differentiation. In our assays when Rybp is absent, Pax6 is upregulated. Since high level of Pax6 obstructs terminal differentiation of NPCs it is possible that this elevated level of Pax6 helps to keep NPCs at the early stage of differentiation and inhibits the forthcoming late neural processes in the rybp ${ }^{-/-}$cells [33] (Figure 5). Upregulation of Nestin and NeuroD1 also confirms that early neural processes are accelerated in the lack of Rybp compared to the wild type. At the same time, silencing of key pluripotency genes (e.g., Oct4, Nanog) is a well coordinated event in the absence of Rybp indicating that improper silencing of pluripotency genes cannot be the causative of the phenotype. The only exception is Sox 2 since the pool of Sox 2 positive cells is reduced in the rybp null mutants earlier than in the wild type neural cultures. Sox 2 is not only a critical factor for maintaining pluripotency and directing the differentiation of stem cells to neural progenitors but it is also important for maintaining the properties of NPCs [15]. Downregulation of Sox 2 resulted in progenitor cells losing capability to both proliferate and terminally differentiate [34]; however to determine how Sox 2 dose-change alters the state of NPCs in neural differentiation is a debate of future studies. Since others already described that striking increase of Pax6 partially rescues the Sox2 mutant phenotype [35], it cannot be excluded that increased level of Pax6 in the null mutant compensates the effect of low level of Sox2. It is possible that the lack of Rybp alters the balance among major transcription factors governing the NPC pool generation and consequent differentiation events. Changing the expression level of one or more members in these circuits will shift the finely tuned balance and initiate premature differentiation. Alternatively, this suboptimal balance may exhaust the NPC pool, which obscures consequent differentiation events, since Rybp is a moonlighting protein and is involved in such diverse biological functions as ubiquitination [3], apoptosis [36], and transcriptional repression [4], and it may have multiple roles in regulating neural differentiation as well. It further complicates the situation that Yaf2 (the other member of the Rybp/Yaf2 gene family) may compensate for the lack of Rybp at certain extent $[37,38]$.

Decreased level of late neuronal markers (Tuj1, NeuN, Gfap, and Olig2) indicates that maturing of neurons, oligodendrocytes, and astrocytes are deficient in the rybp null mutant cells (Figure 5). Parallel with these, the mutant cells seem to form a larger NPC pool (d10) and less astrocytes and oligodendrocytes in comparison to the wild types (d14). Overall, these observations confirm that maturation of neurons, astrocytes, and oligodendrocytes are deficient in the rybp null mutant cells and this process is not lineage specific.

The other gene whose expression is drastically changed in the $r y b p^{-1-}$ neural cultures is Plagll, which is an important regulator of neural development, apoptosis, and cell-cycle arrest whereas it has antiproliferative activity [39, 40]. Plagl1 is normally expressed in the progenitor cells of ventricular zone, subventricular zone, and external granular cell layer of the brain and promotes cell-cycle withdrawal of NPCs during the differentiation processes [10]. The tight regulation of cell-cycle processes is required to ensure timely generation and correct amount of the various neural cell types, which largely depends on the presence of Plagll. The observation that Plagll is almost completely downregulated in the absence of functional Rybp and the fact that Rybp and Plagll deficient mice exhibit similar development defects (reduced number of mature neurons, reduced size of cerebellum, etc.) indicate a possible genetical or biochemical link between Rybp and Plagl1 $[8,9]$. In our study increased level of Pax6 is accompanied by the downregulation of Plagll in Rybp deficient cells. In the absence of functional Rybp it is very likely that the balance of early and late neural processes is "unbalanced," which is probably linked to the upregulation of Pax6 and/or the loss of Plagll (Figure 5).

Possibilities for action of Rybp are likely very diverse. Recent studies showed that Rybp is a member of the recently 


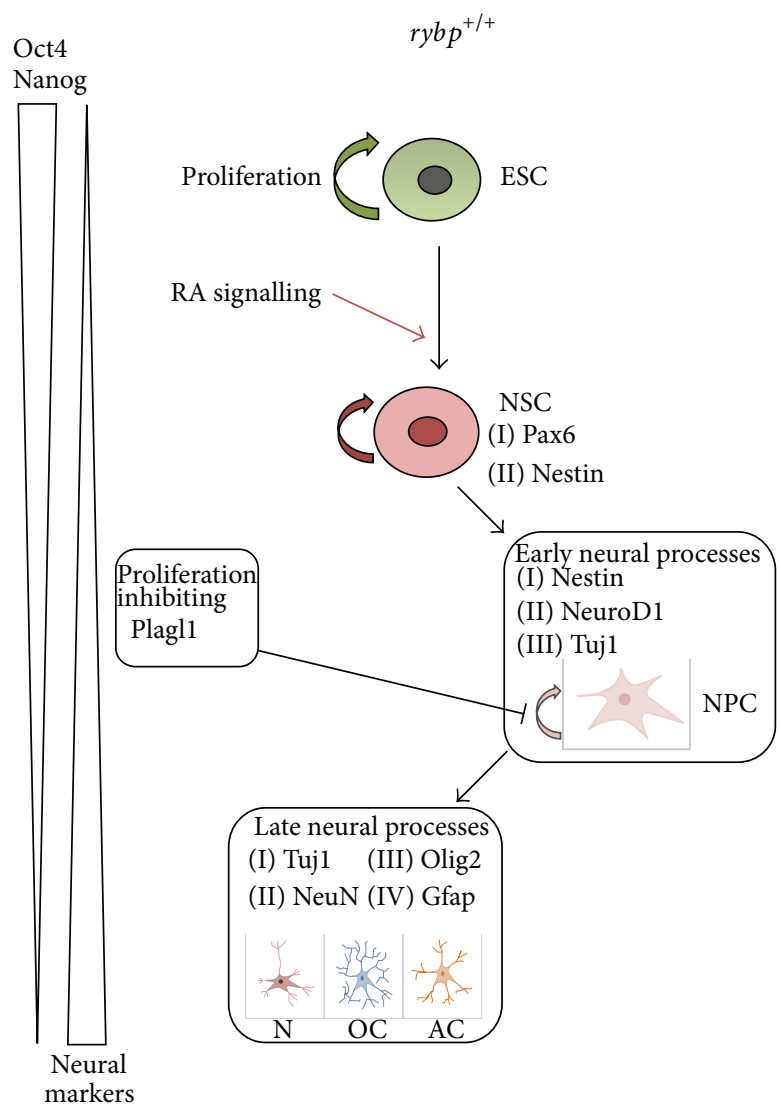

(a)

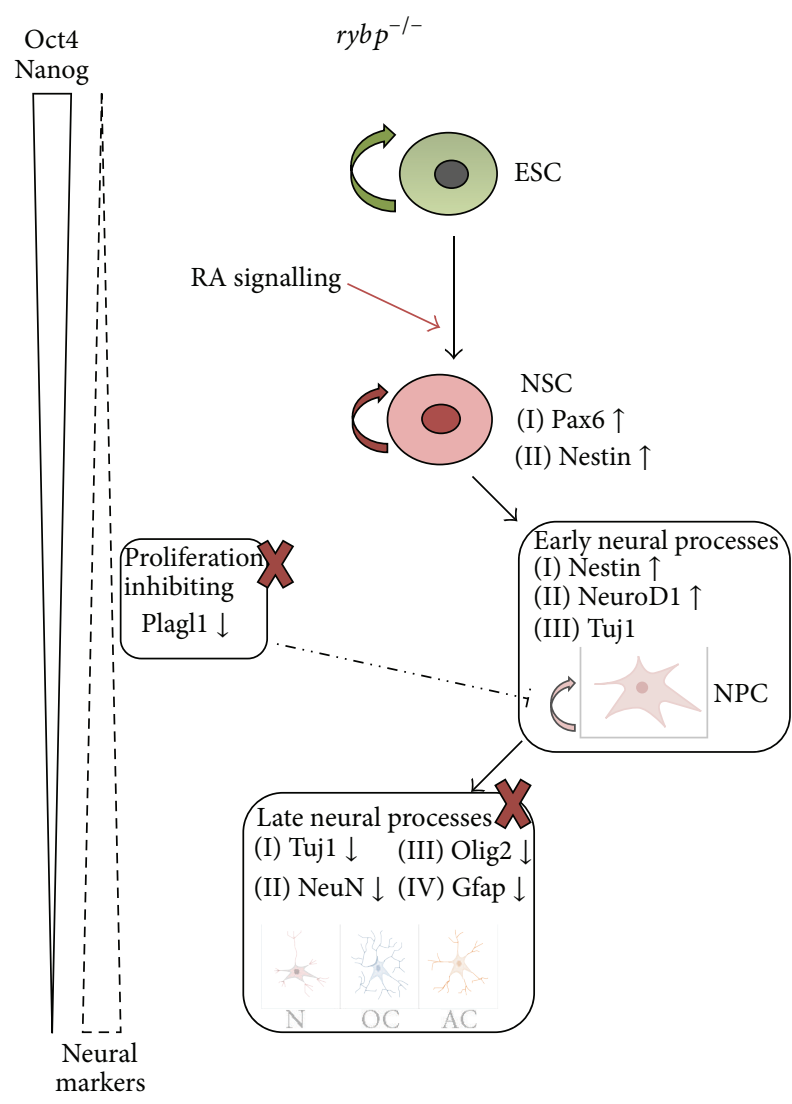

(b)

FIGURE 5: Model of in vitro neural differentiation in ESCs in presence and absence of Rybp. (a) Differentiation of wild type ESCs towards matured cell types of the CNS in the presence of Rybp. Pluripotent ESCs express key pluripotency markers (e.g., Oct4, Nanog) in undifferentiated state, which are gradually decreasing through in vitro neural differentiation. Parallel with this, early neural markers (Pax6, Nestin) are upregulated in NSCs, which will confer reduced proliferative and high differentiation capacity to the cells. On the other hand, in the presence of Rybp, upregulation of Plagll helps to facilitate late neural differentiation and inhibits cell proliferation, which will facilitate the generation of terminally differentiated neural cell types (N, OC, and AC). By the progression of neural differentiation, NPCs will differentiate further and start to express markers of specialized neural cell types (Tuj1, NeuN, Olig2, and Gfap). (b) Differentiation of pluripotent ESCs towards matured cell types of the CNS is impaired in the absence of Rybp. During neural differentiation early neural markers (Pax6, Nestin) exhibit elevated expression level in the rybp null mutants. These will facilitate the generation of a bigger pool of NPCs with higher proliferative capacity. On the other hand, in the absence of Rybp, Plagll expression is defective, which also contributes to increased proliferative and decreased differentiation capacity of the NPCs. As a result, the formation of terminally differentiated neural cell types (N, OC, and AC) will be impaired in the lack of functional Rybp. ESC: embryonic stem cell; NSC: neural stem cell; NPC: neural progenitor cell; N: neuron; OC: oligodendrocyte; AC: astrocyte; RA: retinoic acid; CNS: central nervous system.

identified noncanonical PRC1 complex with unknown biological functions [41]. This complex is also encompassing $\mathrm{Kdm} 2 \mathrm{~b}$, a gene with essential function during embryonic development. Notably, loss of $\mathrm{Kdm} 2 \mathrm{~b}$ is perinatally lethal with incomplete neural tube closure, exencephaly, and altered cell-cycle processes in NPCs [42] mimicking the phenotype of the $r y b p$ heterozygous mice [8]. Kdm2b, like Rybp, is also the member of the BCOR complex [5], which also plays important role in neurogenesis suggesting further possible functional cooperation between the two genes [7]. Importantly, members of the PRCs are proven to play important role in neural development: loss of Ring1B, which is core member of the canonical PRC1 and binding partner of Rybp, causes premature neuronal differentiation [43]. Ezh2, a core member of the PRC2, is highly expressed in NPCs and downregulated through the differentiation of mature cortical neurons [44].
Notably, Neurogenin 1, has been found to be suppressed by a PRC mediated mechanism at the neuronal-to-astrocytic transition of NPC differentiation during corticogenesis [45]. To clarify whether Rybp is functioning as the member of PRCs or other multimeric protein complexes during neural development is a debate of future studies.

\section{Conflict of Interests}

The authors state that they have no conflict of interests.

\section{Authors' Contribution}

Melinda K. Pirity and Gergo Kovacs conceived and designed the experiments. Gergo Kovacs and Viktoria Szabo executed 
the experiments. Melinda K. Pirity and Gergo Kovacs analyzed the data. Melinda K. Pirity and Gergo Kovacs wrote the paper.

\section{Acknowledgment}

This work was supported by NKTH-OTKA FP7 "Mobility" HUMAN-MB08C-80205.

\section{References}

[1] E. H. Davidson, J. P. Rast, P. Oliveri et al., "A genomic regulatory network for development," Science, vol. 295, no. 5560, pp. 1669$1678,2002$.

[2] E. Garcia, C. Marcos-Gutiérrez, M. del Mar Lorente, J. C. Moreno, and M. Vidal, "RYBP, a new repressor protein that interacts with components of the mammalian Polycomb complex, and with the transcription factor YY1," The EMBO Journal, vol. 18, no. 12, pp. 3404-3418, 1999.

[3] L. Tavares, E. Dimitrova, D. Oxley et al., "RYBP-PRC1 complexes mediate $\mathrm{H} 2 \mathrm{~A}$ ubiquitylation at polycomb target sites independently of PRC2 and H3K27me3," Cell, vol. 148, no. 4, pp. 664-678, 2012.

[4] S. Schlisio, T. Halperin, M. Vidal, and J. R. Nevins, "Interaction of YY1 with E2Fs, mediated by RYBP, provides a mechanism for specificity of E2F function," The EMBO Journal, vol. 21, no. 21, pp. 5775-5786, 2002.

[5] M. D. Gearhart, C. M. Corcoran, J. A. Wamstad, and V. J. Bardwell, "Polycomb group and SCF ubiquitin ligases are found in a novel BCOR complex that is recruited to BCL6 targets," Molecular and Cellular Biology, vol. 26, no. 18, pp. 6880-6889, 2006.

[6] J. A. Wamstad, C. M. Corcoran, A. M. Keating, and V. J. Bardwell, "Role of the transcriptional corepressor Bcor in embryonic stem cell differentiation and early embryonic development," PLoS ONE, vol. 3, no. 7, Article ID e2814, 2008.

[7] L. Tiberi, J. Bonnefont, J. vandenAmeele et al., "A BCL6/BCOR/SIRT1 complex triggers neurogenesis and suppresses medulloblastoma by repressing Sonic Hedgehog signaling," Cancer Cell, vol. 26, no. 6, pp. 767-812, 2014.

[8] M. K. Pirity, J. Locker, and N. Schreiber-Agus, "Rybp/DEDAF is required for early postimplantation and for central nervous system development," Molecular and Cellular Biology, vol. 25, no. 16, pp. 7193-7202, 2005

[9] S.-H. Chung, H. Marzban, K. Aldinger et al., "Zacl plays a key role in the development of specific neuronal subsets in the mouse cerebellum," Neural Development, vol. 6, no. 1, article 25, 2011.

[10] T. Valente and C. Auladell, "Expression pattern of Zacl mouse gene, a new zinc-finger protein that regulates apoptosis and cellular cycle arrest, in both adult brain and along development," Mechanisms of Development, vol. 108, no. 1-2, pp. 207-211, 2001.

[11] A. Nagy, J. Rossant, R. Nagy, W. Abramow-Newerly, and J. C. Roder, "Derivation of completely cell culture-derived mice from early-passage embryonic stem cells," Proceedings of the National Academy of Sciences of the United States of America, vol. 90, no. 18, pp. 8424-8428, 1993.

[12] T. M. Magin, J. McWhir, and D. W. Melton, "A new mouse embryonic stem cell line with good germ line contribution and gene targeting frequency," Nucleic Acids Research, vol. 20, no. 14, pp. 3795-3796, 1992.
[13] M. Bibel, J. Richter, K. Schrenk et al., "Differentiation of mouse embryonic stem cells into a defined neuronal lineage," Nature Neuroscience, vol. 7, no. 9, pp. 1003-1009, 2004.

[14] S. Masui, Y. Nakatake, Y. Toyooka et al., "Pluripotency governed by Sox 2 via regulation of Oct3/4 expression in mouse embryonic stem cells," Nature Cell Biology, vol. 9, no. 6, pp. 625-635, 2007.

[15] V. Graham, J. Khudyakov, P. Ellis, and L. Pevny, "SOX2 functions to maintain neural progenitor identity," Neuron, vol. 39 , no. 5, pp. 749-765, 2003.

[16] U. Lendahl, L. B. Zimmerman, and R. D. G. McKay, "CNS stem cells express a new class of intermediate filament protein," Cell, vol. 60 , no. 4 , pp. 585-595, 1990.

[17] D. Park, A. P. Xiang, F. F. Mao et al., "Nestin is required for the proper self-renewal of neural stem cells," Stem Cells, vol. 28, no. 12, pp. 2162-2171, 2010.

[18] R. E. Hill, J. Favor, B. L. M. Hogan et al., "Mouse Small eye results from mutations in a paired-like homeobox-containing gene," Nature, vol. 354, no. 6354, pp. 522-525, 1991.

[19] C. Boutin, O. Hardt, A. de Chevigny et al., "NeuroD1 induces terminal neuronal differentiation in olfactory neurogenesis," Proceedings of the National Academy of Sciences of the United States of America, vol. 107, no. 3, pp. 1201-1206, 2010.

[20] M. M. Black, J. M. Cochran, and J. T. Kurdyla, "Solubility properties of neuronal tubulin: evidence for labile and stable microtubules," Brain Research, vol. 295, no. 2, pp. 255-263, 1984.

[21] A. Ferreira and A. Caceres, "Expression of the class III $\beta$ tubulin isotype in developing neurons in culture," Journal of Neuroscience Research, vol. 32, no. 4, pp. 516-529, 1992.

[22] M. L. Fanarraga, "Expression of unphosphorylated class III $\beta$ tubulin isotype in neuroepithelial cells demonstrates neuroblast commitment and differentiation," European Journal of Neuroscience, vol. 11, no. 2, pp. 517-527, 1999.

[23] R. J. Mullen, C. R. Buck, and A. M. Smith, "NeuN, a neuronal specific nuclear protein in vertebrates," Development, vol. 116, no. 1, pp. 201-211, 1992.

[24] C. M. Jacque, C. Vinner, M. Kujas, M. Raoul, J. Racadot, and N. A. Baumann, "Determination of glial fibrillary acidic protein (GFAP) in human brain tumors," Journal of the Neurological Sciences, vol. 35, no. 1, pp. 147-155, 1978.

[25] R. Mizuguchi, M. Sugimori, H. Takebayashi et al., "Combinatorial roles of Olig2 and Neurogenin2 in the coordinated induction of pan-neuronal and subtype-specific properties of motoneurons," Neuron, vol. 31, no. 5, pp. 757-771, 2001.

[26] H. Takebayashi, Y. Nabeshima, S. Yoshida, O. Chisaka, K. Ikenaka, and Y.-I. Nabeshima, "The basic helix-loop-helix factor olig2 is essential for the development of motoneuron and oligodendrocyte lineages," Current Biology, vol. 12, no. 13, pp. 1157-1163, 2002.

[27] Q. Zhou, S. Wang, and D. J. Anderson, "Identification of a novel family of oligodendrocyte lineage-specific basic helixloop-helix transcription factors," Neuron, vol. 25, no. 2, pp. 331$343,2000$.

[28] O. Ujhelly, V. Szabo, G. Kovacs et al., "Lack of rybp in mouse embryonic stem cells impairs cardiac differentiation," Stem Cells and Development, 2015.

[29] T. Valante, F. Junyent, and C. Auladell, "Zacl is expressed in progenitor/stem cells of the neuroectoderm and mesoderm during embryogenesis: differential phenotype of the Zacl-expressing cells during development," Developmental Dynamics, vol. 233, no. 2, pp. 667-679, 2005. 
[30] W. Wang, J. Cheng, J.-J. Qin et al., "RYBP expression is associated with better survival of patients with hepatocellular carcinoma (HCC) and responsiveness to chemotherapy of HCC cells in vitro and in vivo," Oncotarget, vol. 5, no. 22, pp. 1156711582, 2014.

[31] S. Gajović, L. St-Onge, Y. Yokota, and P. Gruss, "Retinoic acid mediates Pax6 expression during in vitro differentiation of embryonic stem cells," Differentiation, vol. 62, no. 4, pp. 187-192, 1998.

[32] J. Ericson, P. Rashbass, A. Schedl et al., "Pax6 controls progenitor cell identity and neuronal fate in response to graded Shh signaling," Cell, vol. 90, no. 1, pp. 169-180, 1997.

[33] S. Bel-Vialar, F. Medevielle, and F. Pituello, "The on/off of Pax6 controls the tempo of neuronal differentiation in the developing spinal cord," Developmental Biology, vol. 305, no. 2, pp. 659-673, 2007.

[34] O. V. Taranova, S. T. Magness, B. M. Fagan et al., "SOX2 is a dose-dependent regulator of retinal neural progenitor competence," Genes and Development, vol. 20, no. 9, pp. 11871202, 2006.

[35] D. Matsushima, W. Heavner, and L. H. Pevny, "Combinatorial regulation of optic cup progenitor cell fate by SOX2 and PAX6," Development, vol. 138, no. 3, pp. 443-454, 2011.

[36] L. Zheng, O. Schickling, M. E. Peter, and M. J. Lenardo, "The death effector domain-associated factor plays distinct regulatory roles in the nucleus and cytoplasm," Journal of Biological Chemistry, vol. 276, no. 34, pp. 31945-31952, 2001.

[37] T. Kaneko, H. Miyagishima, T. Hasegawa, Y. Mizutani-Koseki, K.-I. Isono, and H. Koseki, "The mouse YAF2 gene generates two distinct transcripts and is expressed in pre-and postimplantation embryos," Gene, vol. 315, no. 1-2, pp. 183-192, 2003.

[38] C. Sawa, T. Yoshikawa, F. Matsuda-Suzuki et al., "YEAF1/RYBP and YAF-2 are functionally distinct members of a cofactor family for the YY1 and E4TF1/hGABP transcription factors," Journal of Biological Chemistry, vol. 277, no. 25, pp. 2248422490, 2002.

[39] A. Abdollahi, D. Roberts, A. K. Godwin et al., "Identification of a zinc-finger gene at 6q25: a chromosomal region implicated in development of many solid tumors," Oncogene, vol. 14, no. 16, pp. 1973-1979, 1997.

[40] D. Spengler, M. Villalba, A. Hoffmann et al., "Regulation of apoptosis and cell cycle arrest by Zacl, a novel zinc finger protein expressed in the pituitary gland and the brain," The EMBO Journal, vol. 16, no. 10, pp. 2814-2825, 1997.

[41] X. Wu, J. V. Johansen, and K. Helin, "Fbxl10/Kdm2b recruits polycomb repressive complex 1 to $\mathrm{CpG}$ islands and regulates H2A ubiquitylation," Molecular Cell, vol. 49, no. 6, pp. 1134-1146, 2013.

[42] T. Fukuda, A. Tokunaga, R. Sakamoto, and N. Yoshida, "Fbxl10/Kdm2b deficiency accelerates neural progenitor cell death and leads to exencephaly," Molecular and Cellular Neuroscience, vol. 46, no. 3, pp. 614-624, 2011.

[43] M. Román-Trufero, H. R. Méndez-Gómez, C. Pérez et al., "Maintenance of undifferentiated state and self-renewal of embryonic neural stem cells by polycomb protein Ring1B," Stem Cells, vol. 27, no. 7, pp. 1559-1570, 2009.

[44] A. Sparmann, Y. Xie, E. Verhoeven et al., "The chromodomain helicase Chd4 is required for Polycomb-mediated inhibition of astroglial differentiation," The EMBO Journal, vol. 32, no. 11, pp. 1598-1612, 2013.

[45] G. Testa, "The time of timing: how Polycomb proteins regulate neurogenesis," BioEssays, vol. 33, no. 7, pp. 519-528, 2011. 

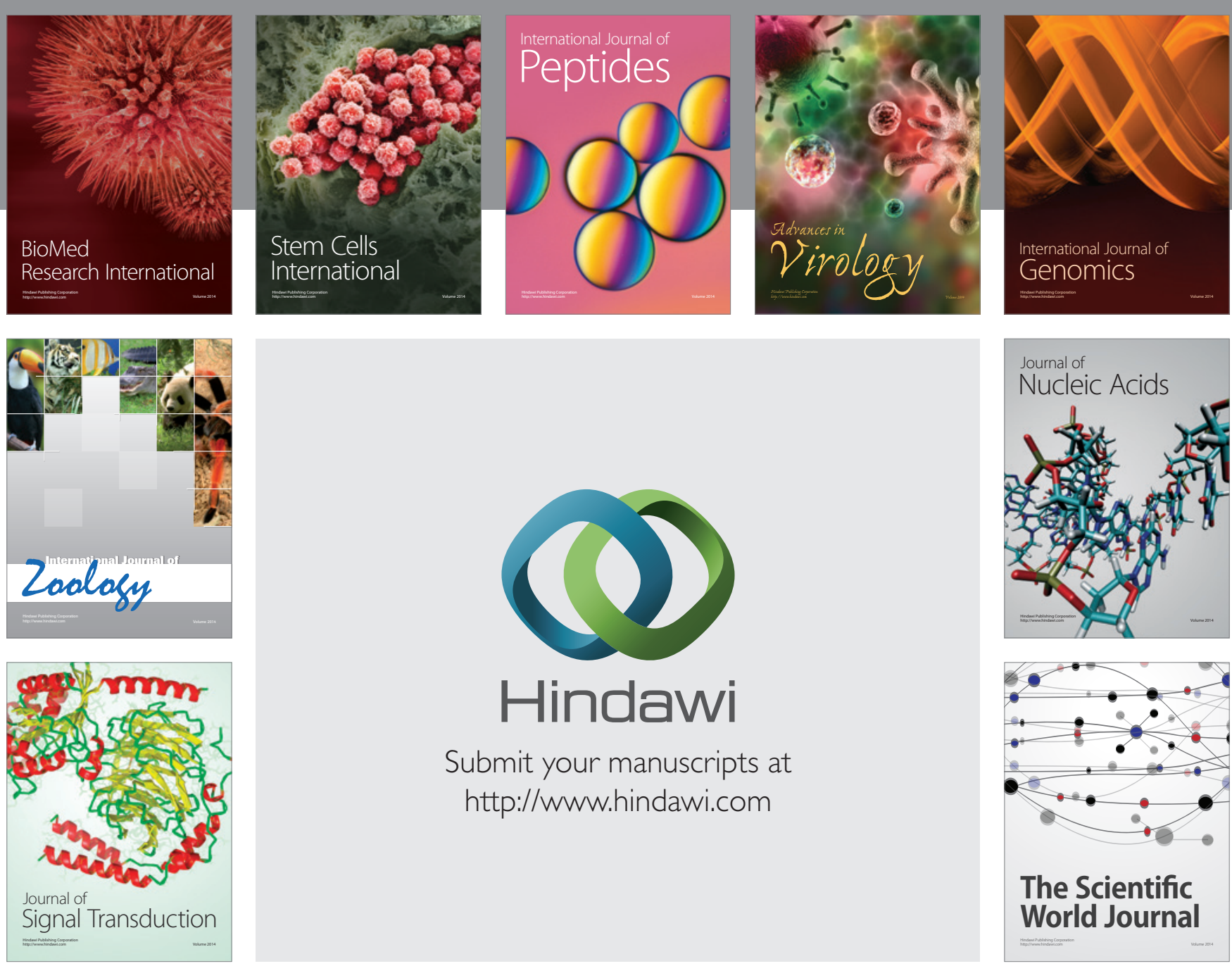

Submit your manuscripts at

http://www.hindawi.com
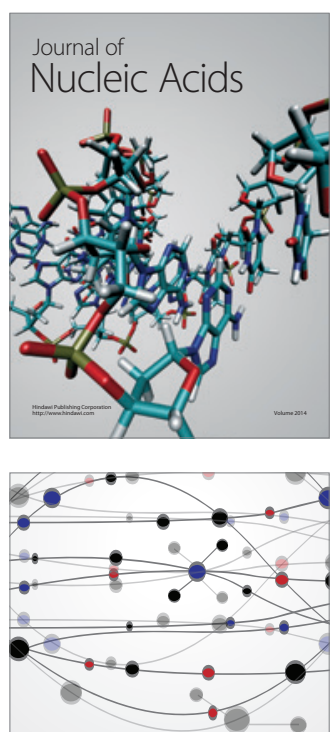

The Scientific World Journal
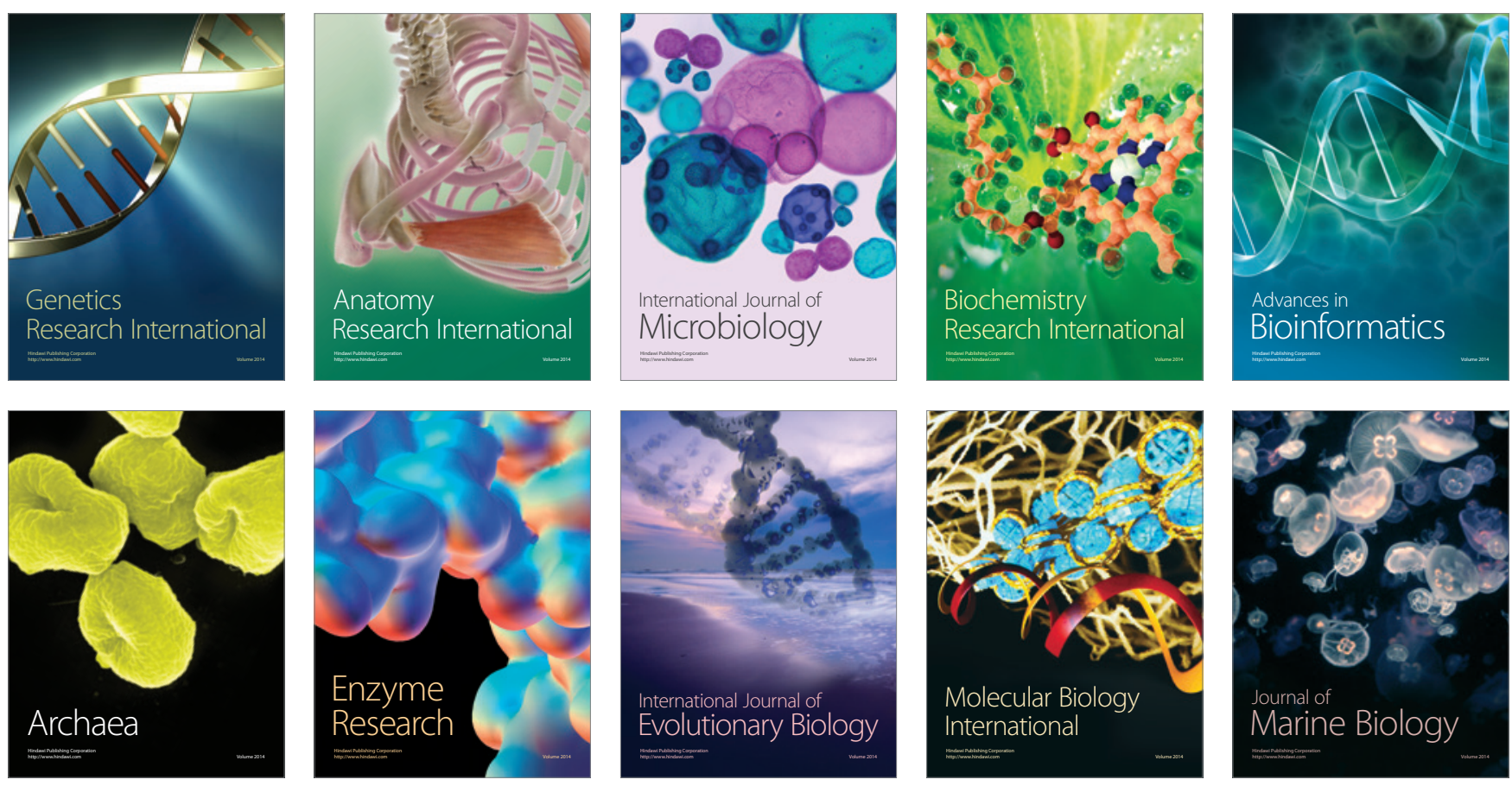